SECTION THREE.

Possibilities of Applying LegalTech Tools in Legal Practice 



\title{
The Changing Role of the Lawyer. The Case of Digital Accessibility.
}

\author{
Ewa Fabian, Przemystaw Polański
}

\section{Introduction}

The role of the lawyer will change due to the technological revolution, additionally accelerated by the COVID-19 pandemic. While it is unlikely that a lawyer will be replaced by artificial intelligence, it is becoming more and more realistic to replace some of a lawyer's activities with more and more specialized LegalTech tools. The chapter aims to introduce the issues of ensuring digital accessibility ${ }^{1}$ with the use of new tools available to a technology lawyer. These tools allow, for example, to automatically assess the compliance of public authorities' websites with the provisions of domestic and EU law. However, one should not jump to too hasty conclusions from the existence of such tools. Humans maintain the most important role in the process of ensuring compliance.

In a brilliant futurological analysis, "The Future of the Professions: How Technology Will Transform the Work of Human Experts" R. and D. Susskind propose that although artificial intelligence will not replace all lawyers, it will replace expensive lawyers. The authors predict that in the post-professional society, practical knowledge will be available on the Internet, ${ }^{2}$ and this in turn will trigger not so much a violent revolution as an incremental digital transformation of the profession. Field experts will gradually be replaced by a cheaper workforce capable of handling intelligent LegalTech solutions. The model of the lawyers' work will fundamentally change, as they will be surrounded by new technologies that will help them solve current problems in a previously unknown manner.

1 These findings result from empirical research on digital accessibility from the perspective of people with visual disabilities, carried out by the FREE Institute in the project "Model of making content available on the Internet to people with disabilities in accordance with applicable national and international law and WCAG 2.0 principles" NCN grant no. 2016/22/E/HS5/00434, within which this chapter was prepared.

2 Richard Susskind and Daniel Susskind, The Future of the Professions (Oxford University Press 2015), see in particular the Authors' final conclusions. 
This will mean that lawyers who will be able to use new technologies to provide cheaper and faster services will survive, not the lawyers with extensive trial experience.

Can the Susskinds' new vision really come true in Poland? Nothing can be ruled out but it seems unlikely. To build AI systems that are able to replace the elite of jurists you will need the foundations of well-developed legal knowledge databases which are an indispensable component of selflearning systems. While you do not need a good deal of imagination to see the operation of document or clauses classification systems that are already quite often used in due diligence processes, the creation of autonomous systems resolving disputes between parties or recommending a cause of action in a manner consistent with generally applicable law is an incomparably more difficult task.

There is a lack of foundations in the form of perfectly developed databases of normative acts and jurisprudence, as well as a stable legal system and court judgments that would clearly apply the provisions "for a specific date" and clearly refer to the essence of previous judgments. To this day, we have not lived to see an open legal information system that would make available not only unified versions of laws, but also of regulations. This remark applies not only in the PDF versions of such acts (difficult to process automatically), but in open formats such as HTML or XML. ${ }^{3}$

We also have no databases of judgments that would allow assigning the interpretation of provisions to precisely indicated legal grounds. When analyzing the content of grounds for judgments, it is impossible to indicate the temporal version of the interpreted provision, which, taking into account the level of legal inflation, significantly hinders the creation of a state system of legal information. As a result, it is impossible to determine which version of the regulations was used by the adjudicating panel, which in turn significantly hinders the construction of intelligent legal information systems.

This does not mean that lawyers do not have access to excellent databases of legal information. Lex and Legalis have revolutionized the way legal practice functions in Poland in such a way that today's lawyers actually only need a legal information system and a mobile phone to be able to provide legal services remotely. Thanks to these systems, we can precisely determine the laws applicable for a specific date, find related judgments,

3 Przemysław Paul Polański, (C. H. Beck LegalTech Forum conference, Warszawa, 16-17 June 2021). 
and contextually delve into the reading of the doctrinal legal elite. Undoubtedly, this allows lawyers who do not belong to the juristic elite to provide services in the model described by the Susskinds today. Nevertheless, we are still a long way from the systems that automatically solve a specific legal issue.

This chapter also examines the changing role of the lawyer as a part of the digital revolution that has gained additional acceleration in the context of the COVID-19 pandemic. In order to make this chapter more specialized, we will show, on the example of digital accessibility, how the role of a lawyer is currently changing and how much will depend on the adaptation of the legal education system, where digital skills should be developed, instead of leaving this issue practically completely outside the main curriculum of young lawyers.

\section{Case study: using LegalTech tools in measuring digital accessibility}

Digital accessibility as a legal issue is new and little known to Polish lawyers, although, over the recent months, the websites of most public sector bodies have started to provide accessibility statements. This is the result of the implementation of Directive 2016/2102 ${ }^{4}$ into Polish law, which obligated public authorities to adopt a new approach to serving content on websites and mobile applications in such a way that people with various types of disabilities - whether temporary or permanent - could access content. The aforementioned implementation took place in the Act of 4 April 2019 on digital accessibility of websites and mobile applications of public entities ${ }^{5}$ (the Act on Digital Accessibility).

Investigating whether a public administration body actually complies with the applicable regulations requires lawyers to learn about the socalled assistive technology and foundations of empirical research, in line with the basic idea of social sciences (which includes legal science). The above observations should make it clear that testing the digital accessibility of websites for people with visual disabilities requires a deep understanding of new IT tools. Testing digital accessibility should not be imagined

4 European Parliament and Council Directive 2016/2102 of 26 October 2016 on the accessibility of the websites and mobile applications of public sector bodies [2016] OJ L327/1, requiring accessibility statements differing from the existing accessibility declarations, published on the websites of Polish public entities earlier.

5 Dz.U. 2019 poz. 848; see also Przemysław Paul Polański (ed.), Ustawa o dostępności cyfrowej. Komentarz (1st edn, C.H.Beck 2021). 
as manual work or reading source code without an additional IT environment, but as work involving the use of various types of software. Thus, even without describing in detail the functionalities of programs used for assessing digital accessibility, which are more and more available on the market, and which may be designed basing on various presumptions, ${ }^{6}$ it can be assumed that the analysis of digital accessibility cannot be carried out by an expert in isolation from specific technology and software.

Below, we will present the Reader with a study on the issue of ensuring digital accessibility of websites keeping in mind the needs of people with visual disabilities. This is just one, albeit very important, aspect of digital accessibility. The process in question requires the selection of software (one or several programs), the ability to use it and understanding the impact of decisions made on the measurement results, and thus the use of specific methods of working with a given $\operatorname{program}(s)$. We note here, however, that digital accessibility concerns good user experience for all users, which explains why the most accessible websites are also very popular (e.g. Google search engine).

\section{Lawyer's analysis of digital accessibility - methodology}

Before we move on to discussing the IT tools used in digital accessibility research, let us first look at the legal framework regulating the process of ensuring compliance by the entities which the Act on Digital Accessibility addresses. At the outset, it is worth emphasizing that the international technical standard called WCAG (Web Content Accessibility Guidelines) has become an integral part of Polish law for many years (acts regulating digitization, the Act on Digital Accessibility). The development, testing, changes and translations of this standard are the result of the work of an international and diverse community of experts, ${ }^{7}$ which in itself is another proof of the viability of the lex mercatoria informatica concept, i.e. custom created bottom-up by the Internet community. ${ }^{8}$

6 See also the list maintained by the World Wide Web Consortium (W3C): https://w ww.w3.org/WAI/ER/tools/ (accessed on 25/03/2021).

7 More about this process on the W3C website, Web Accessibility Initiative (WAI) - <https://www.w3.org/WAI/standards-guidelines/wcag/> accessed on 25 March 2021.

8 Przemysław Paul Polański, Customary law of the Internet (1st edn, T.M.C. Asser Press 2007) in which the author constructs the theoretical foundations of the 
As the law requires public sector bodies to ensure digital accessibility, the question arises as to how the measurement of the level of digital accessibility is to be made. Directive 2016/2102 refers to this indirectly in several provisions, e.g. in Art. 8 Sec. 3.(f), where reference is made to a monitoring methodology that "may take into account expert analysis" and includes "appropriate arrangements, including where necessary examples and guidance, for automatic, manual and usability tests, in combination with the sampling settings, in a way which is compatible with the periodicity of the monitoring and reporting".

When examining digital accessibility in the legal context, in accordance with the law of the Republic of Poland, attention should be paid to the need to conduct empirical research, which has so far been alien to legal science. In the very provisions of the Act on Digital Accessibility, there is a reference to the European standard, ${ }^{10}$ the application of which will require the lawyers of the future to be able to use tools used for measuring accessibility compliance by the public sector bodies, and soon - also by the entities of the private sector.

Commission Implementing Decision 2018/152411 concerning the implementation of Directive 2016/2102 contains detailed provisions on monitoring to be carried out by competent local supervisory authorities across the EU.

The core monitoring methodology set out in Implementing Decision 2018/1524 includes an in-depth monitoring methodology that:

custom as a source of law on the Internet and the methods of proving it with the use of information technology and social science methodology.

9 Directive 2016/2102 (n 399) is technology neutral (see recitals 9 and 36 thereof). Existing industry standards (WCAG) are also technology neutral. In practice, however, some aspects described in the regulations relate to specific technical solutions. For example, point 1.3.2 of Implementing Decision 2018/1524, which deals with use by blind persons, refers to assistive technology that allows a blind person to listen to the content of a website (e.g. a screen reader which is a computer program).

10 Currently, in the version of EN 301549 V2.1.2, which includes Standard W3C - Web Content Accessibility Guidelines 2.1, Recommendation W3C 5.6.2018; see https://www.w3.org/TR/WCAG21/ access 25 March2021.

11 Commission Implementing Decision 2018/1524 of 11 October 2018 establishing a monitoring methodology and the arrangements for reporting by Member States in accordance with Directive (EU) 2016/2102 of the European Parliament and of the Council on the accessibility of the websites and mobile applications of public sector bodies [2018] OJ L256/108. 
1) verifies all the steps of the processes in the sample, following at least the default sequence for completing the process;

2) evaluates at least the interaction with forms, interface controls and dialogue boxes, the confirmations for data entry, the error messages and other feedback resulting from user interaction when possible, as well as the behaviour of the website or mobile application when applying different settings or preferences;

3) may include, where appropriate, usability tests such as observing and analysing how users with disabilities perceive the content of the website or mobile application and how complex it is for them to use interface components like navigation menus or forms. ${ }^{12}$

On the other hand, the Implementing Decision 2018/1524 specifies simplified monitoring, which is carried out using automated tests and analyzes (point 1.3.2):

1) usage without vision;

2) usage with limited vision;

3) usage without perception of colour;

4) usage without hearing;

5) usage with limited hearing;

6) usage without vocal capability;

7) usage with limited manipulation or strength;

8) the need to minimise photosensitive seizure triggers;

9) usage with limited cognition.

Directive 2016/2102 and Implementing Decision 2018/1524 show the conviction that IT tools for the automatic analysis of the level of digital accessibility will develop, becoming less unreliable in the future and requiring less interpretative input from the analyst. We may assume that this type of technology can also be developed with the use of machine learning techniques (technologies usually more broadly referred to as the so-called artificial intelligence - AI). We are currently in the period of technological development, when the human factor is still treated as necessary to test the level of digital accessibility, but, at the same time, the existing technologies allowing for partial automation of this process are already included in applicable regulations. The development of legislation requires resorting to technical standards and empirical research. The provisions cited above clearly show one more aspect of the changing role of the lawyer. The

12 See point 1.2.2. - 1.2.4. of Implementing Decision 2018/1524. 
lawyer of the future will have to be able to use, to a greater extent, not only the tools, but also the methodologies of ensuring compliance with the provisions expressed directly in the provisions of law.

\section{Assistive technology - a new weapon in the LegalTech lawyer's arsenal?}

Testing digital accessibility requires a very good knowledge of web browsers through which the content is downloaded and also the so-called screen readers which help the visually impaired people read the content, e.g. free $\mathrm{NVDA}^{13}$ or paid JAWS. This means that testing the level of digital accessibility will require the skills of a digital accessibility lawyer to use such programs, not just word processors or legal information databases. Incidentally, it is worth adding that the use of such computer programs as assistive technologies raises further problems, including:

1) the transparency of the operation of such programs;

2) trust in programs on the part of law enforcement authorities and parties in court;

3) criteria for assessing the validity of the work of a lawyer or expert in the context of court proceedings.

Questions that can be asked in this context are whether a computer program is able to "lie", what should be the standards for examining the way the program works, or whether the related problem of the so-called black box (i.e. the impossibility to observe the internal mode of operation) differs significantly from the assessment of the reliability of e.g. expert dogs (such as in drug cases - drug dogs), as well as what level of knowledge of the program should be required from a lawyer. By introducing technologies in the work of a lawyer to the courtroom, these aspects fit into the broadly understood subject of LegalTech.

\section{Case study:}

In this context, it is worth referring to the American experience (which we will discuss in more detail later in this work). In the case of Andrews $v$. Blick Art Materials, ${ }^{14}$ the judgment stated that, according to international research, the majority of Internet users used the paid JAWS technology. It cited a 2015 report according to which $30.2 \%$ of screen reader users were

13 See <https://www.nvaccess.org/> accessed 25 March 2021.

14 Andrews v. Blick Art Materials LLC 286 F Supp 3d 365 (NY 2017) 
using JAWS, and the list also included ZoomText (22.2\%), Window-Eyes (20.7\%), NVDA (14, $6 \%$ ), VoiceOver (7.6\%), System Access or System Access To Go $(1.5 \%)$, ChromeVox $(0.3 \%) .{ }^{15}$ It is worth adding that in 2017 the percentages for reader users included: JAWS (46.6\%), NVDA (31.9\%), VoiceOver (11.7\%), ZoomText (2.4\%), System Access or System Access To Go (1.7\%), Window-Eyes (1.5\%), ChromeVox (0.4\%), and Narrator $(0.3 \%){ }^{16}$

In 2019, NVDA outperformed JAWS in the WebAIM longitudinal study: NVDA (40.6\%), JAWS (40.1\%), VoiceOver (12.9\%), ZoomText / Fusion (2.0\%), System Access or System Access To Go (1.0\%), Narrator $(1.0 \%)$, ChromeVox $(0.6 \%) .{ }^{17}$ These values are different when surveying blind people, not all people using screen readers. This research was performed on a fairly small sample, for an international context (sample 1224 in 2019). As reported in the 2017 Andrews v. Blick Art Materials judgment, the JAWS reader cost $\$ 900-1,100$ at the time of the trial.

NVDA is a free technology. Using it requires learning about keyboard shortcuts (tabs, arrows, letter shortcuts allowing the user to jump to specific types of page elements, etc.). These shortcuts allow people who cannot see the content of a website to navigate through the page (NVDA relies on keyboard shortcuts, but also creates a solution for blind people to use the mouse; see NVDA's documentation for more detail). ${ }^{18}$

\section{Tools for testing digital accessibility in American court proceedings}

Digital accessibility is an issue deeply embedded in Western legal doctrine and American courts have been settling disputes over it for a few decades. What's more, the number of digital accessibility cases in US courts is steadily increasing. According to UsableNet analyzes, in 2020, despite epidemiological problems, there was a $23 \%$ increase in the number of court cases related to digital accessibility compared to the previous year. ${ }^{19}$ The number of published judgments related to this subject is also significant. The question of the admissibility of expert testimony regarding the level of

$15<$ https://webaim.org/projects/screenreadersurvey6/> accessed 25 March 2021.

16 <https://webaim.org/projects/screenreadersurvey7/> accessed 25 March 2021.

$17<$ https://webaim.org/projects/screenreadersurvey8/> (accessed 25 March 2021.

18 See reference to the relevant documentation (in original to Polish version): $<$ https://nvda.pl/podrecznik-uzytkownika> accessed 25 March 2021.

19 See <https://info.usablenet.com/2020-report-on-digital-accessibility-lawsuits> accessed 25 March 2021. 
digital accessibility of the defendant's website appeared in this jurisprudence at least twice (the cases of Gomez v. General Nutrition ${ }^{20}$ and Diaz v. Lobel's of New York ${ }^{21}$. The courts mention the so-called Daubert's Standard (regarding Federal Rule of Evidence 702), according to which, when admitting expert evidence, the court checks whether:

1) the expert is qualified to testify competently;

2) the methodology by which the expert reaches his conclusions is sufficiently reliable;

3) the testimony assists the trier of fact, through the application of scientific, technical, or specialized expertise, to understand the evidence or to determine a fact in issue. ${ }^{22}$

What is important in this context are features such as expertise (obtained through knowledge, skills, experience, training or education), reliability and usefulness (the relationship between an expert opinion and the case under examination) and reliability, tested on the basis of reliable principles or methods.

The measure used to assess reliability includes considering:

1) whether the expert's theory can be and has been tested;

2) whether the theory has been subjected to peer review and publication;

3) the known or potential rate of error of the particular scientific technique; and

4) whether the technique is generally accepted in the scientific communi$t^{23}$, and similar criteria are applied to the testimony of experts who have given an opinion based on experience.

\section{Case study:}

In the case of Gomez v. General Nutrition Corp. the expert's opinion was excluded from the evidence, the court indicating that the expert did not know the success criteria of the accessibility checking software relied upon, also taking into account the fact that the expert did not run these tests personally.

In the case of Diaz v. LOBEL'S OF NEW YORK, the court considered whether: 1) the testimony was grounded on sufficient facts or data; 2) the testimony was the product of reliable principles and methods; and

20 Gomez v. General Nutrition Corp. 323 F Supp 3d 1368 (FL 2018)

21 Diaz v. Lobel's of New York LLC 16-CV-6349 (NY 2019).

22 Gomez v. General Nutrition Corp. and case law quoted therein.

23 ibid. 
whether 3) the witness has applied the principles and methods reliably to the facts of the case. ${ }^{24}$ It was argued in the case that the expert failed to disclose any information about the process or methodology used to conduct the 'audit' of the website. This argument was that he failed to disclose any information concerning "what the audits entailed, how they were performed, what the audits were designed to accomplish, what standards were used to conduct the audits, or whether the method by which he performed the audits is accepted within his field". ${ }^{25}$ The court found insufficient the contents of the "manual" describing the audit procedure, which was to include two steps: website code analysis by programmers to test the level of meeting the WCAG 2.0 success criteria A and AA (described as the first step) and analysis using automated tools to verify the results of step one and identify other issues (step two). The screen recording videos of the party's audit process provided to the court by the expert were not a sufficient replacement for a proper explanation of overall methodology and process.

\section{Software used in expert witness testimony in the US and Poland}

In Poland, there have been no court cases deciding the admissibility of an expert witness testimony regarding digital accessibility so far. However, in the judgments concerning the use of software in general, certain issues worthy of careful preliminary description can be identified. In the judgment of the Court of Appeal in Katowice of 5 February 2020, ${ }^{26}$ the court assessed the issue of the correctness of vehicle valuation made with the use of specialized software. The court was convinced by the opinion issued by the court expert, but was not convinced enough by the private expert witness submitted by a party, explaining that "the significant difference between the value of the vehicle resulting from the opinion prepared on private commission before the sale of the vehicle and its value determined by the court expert results from the adoption of a different methodology in the process of valuation performed with the use of specialized software. The expert convincingly explained that in the case of the Bank, the value of the vehicle in question should be valued according to the program in the "sale" version, as the Bank does not deal with professional trade in motor

24 Diaz v. Lobel's of New York LLC and case law quoted therein.

25 ibid.

26 I ACa 504/19, Legalis. 
vehicles and should strive to obtain the highest possible price from the sale. The situation is different in the case of an entity engaged in such trade. Such an entity must bear in mind the need to resell the vehicle and obtain a margin equal to the difference between the purchase price and the next sale price. In such a case, the prospective buyer determines the price of the vehicle by estimating it in the "purchase" version, which leads to a 10-15\% lower value of the vehicle."

The use of software supporting the valuation process is an issue so important in the practice of Polish courts that there are professional publications on this subject. In this context, M. Chmielinski mentions the Polish InfoEkspert system and the Eurotax system adapted from the German market. The Author describes that the foundations of databases enabling valuation support appeared as early as 1933 in the catalog under the name "Glass's Guide to Car Values"; he also provides that expert witness opinions prepared on the basis of such programs are taken seriously: "the Eurotax system is well-known and regarded as reliable, and the Eurotax system products are tailored to the individual requirements of individual user groups. The Eurotax system includes many solutions, from databases and catalogs to integration with internal systems ". ${ }^{27}$

Modeling and computer simulations were defined by M. Chmielinski as the third (interdisciplinary) method, next to the experimental (empirical) and theoretical procedures. This approach is useful in the context of the topic discussed in this chapter, because digital accessibility testing involves elements of a computer simulation (where there is an automatic analysis of potential digital accessibility errors), but at the same time an experiment (e.g. listening to a page using a screen reader) and theoretical analysis (analysis of code, e.g. in terms of the correctness of syntax or the ways of marking code fragments for readers in accordance with their actual purpose). The understanding of this multifaceted nature of tests carried out with the participation of experts is found in Polish jurisprudence. For example, in the judgment issued by the District Court in Świdnica 14 September $2018^{28}$ (in a criminal case), the court emphasized that the expert must conduct experiments on the tested equipment (in this case - slot machines): "during the re-examination of the case, the Regional Court will be obliged to conduct the evidentiary proceedings in full, in

27 Mirosław Chmieliński, 'Możliwości wspomagania wybranych ekspertyz i opinii specjalistycznych w obszarze bezpieczeństwa przy wykorzystaniu różnych programów komputerowych' (2017) 8 2(28) Problemy mechatroniki. Uzbrojenie, lotnictwo, inżynieria bezpieczeństwa 159-176.

28 IV Ka 290/18, Legalis. 
particular, to admit evidence from a supplementary opinion (...) of an expert in the field of computer science and computer software. The expert should inspect the machines and installed software and, in addition to the questions presented by the Regional Court, answer the question whether and what relationship existed between the platform (...) and the running of games, in particular whether the game could be run independently of the software (... .). The expert should also take an opinion on the way the experiment was carried out by customs officers on these machines and assess the correctness of their operation in this regard and the conclusions drawn. When re-examining the case, the court should make a reservation that the expert should secure the connection of the devices in question with the Internet before issuing the opinion".

As M. Szmit describes, in Poland, experts testifying in cases involving software struggle with the problem of the need to evaluate the source code. The Author described his experience in which he had to "comment on a computer program, the source code of which and the resulting program were not included in the presented material. Of course, formally it was probably possible to issue an inconclusive opinion, but it was much better and more reasonable from the point of view of the economy of the proceedings to ask the court to supplement the evidence and to provide the subject of the analysis". Further adding that "it is hard to consider such a request as suggesting a specific tactic for the case", ${ }^{29}$ a question widely discussed in the legal doctrine on the taking of evidence, as well as in jurisprudence. The issue of the reliability of tools used by experts in computer forensics is, as the Author points out, supplemented with standardization (American National Standards Institute, which issued several standards for testing computer devices) and the creation of industry standards and guidelines (The Scientific Working Group on Digital Evidence, which develops guidelines on detailed technical aspects of computer forensics, and The Scientific Working Group on Imaging). ${ }^{30}$ With the exception of a few historical examples, the lack of current Polish initiatives in this area shows how important the issue of reliability of software is for the American jurisdiction.

In a study related to the American jurisprudence of 2010 (S. Bratus, A. Lembree, A. Shubina), there appears a problem of excessive trust in new tech-

29 Maciej Szmit, 'Biegły informatyk w postępowaniu cywilnym' (2010) 121/1078 Zeszyty Naukowe Politechniki Łódzkiej 487-501.

30 Maciej Szmit, 'O standardach informatyki śledczej' (2018) 355 Studia Ekonomiczne 81-91. 
nology on the part of courts. The Authors emphasized the need to question the reliability of technology which in itself may in theory seem impartial (the Authors used a wording in which the machine was treated as an objective learned fool - idiot savant). However, the way the program is written (which is why access to the source code is so important), as well as the database used in it, can affect the operation of the program. Therefore, the Authors suggest that expert witness testimony should be conducted in such a way that the persons performing the tests with the use of such software testify before the court, and the documentation concerning the correct operation of a program or machine is available to be analysed as evidence. ${ }^{31}$ A similar problem is pointed out by the Polish author M. Chmielinski, who calls it "illusory credibility".32[0B] Apart from the description of procedural guarantees allowing for "deep" evidence submissions and considering the reliability of expert witnesses in American jurisprudence, the results of the 2010 research on the use of software in expert witness testimony in the US provoke questions about the future of expert witness testimony where machine learning software is used.

As is well known, solutions simulating the so-called artificial intelligence (AI), in particular machine learning techniques, work in a way that is difficult to observe. They are referred to as "black boxes", i.e. (as already mentioned) a situation in which we may learn the data entered into the program and the result of the analysis, but we cannot observe the inner process of the analysis. As indicated by $P$.W. Nutter, this issue is similar to the doubts one might have about the findings of drug dogs. ${ }^{33}$ The Author points out that machine learning technologies can contribute to the justice system (e.g. by performing lip reading, in the absence of an audio track; by approximating features of the perpetrator from the DNA trace analysis; mentioning that DNA analysis using TrueAllele has gained the trust of the authorities by practical elimination of the "human factor" - laboratory technician - from the test). ${ }^{34}$ According to the Author, machine learning techniques can pass the Daubert Standard test (discussed above).

31 Sergey Bratus, Ashlyn Lembree and Anna Shubina, 'Software on the witness stand: what should it take for us to trust it?' in Alessandro Acquisti, Sean W Smith, Ahmad-Reza Sadeghi (eds), Trust and Trustworthy Computing, Third International Conference, TRUST 2010, Berlin, Germany, June 21-23, 2010, Proceedings (Springer 2010) 396-416.

32 Chmieliński (n 27).

33 Patrick W. Nutter, 'Machine learning evidence: admissibility and weight.' 21 (2018) U. Pa. J. Const. L. 919.

34 ibid. 


\section{Summary}

The role of the lawyer will change due to the technological revolution, additionally accelerated by the COVID-19 pandemic. While it is unlikely that lawyers will be replaced by artificial intelligence, it is becoming more and more realistic to replace some of their activities with more and more specialized LegalTech tools. The chapter discussed analyses into ensuring digital accessibility with the use of new tools in the arsenal of a technology lawyer, such as NVDA. Tools such as these make it possible to assess the compliance of public authorities' websites with domestic and EU law with the use of technology. However, one should not jump to too hasty conclusions from the existence of such tools. The human factor remains the most important link in the compliance process. 